\title{
A comparison between electrocaloric and magnetocaloric materials for solid state refrigeration
}

\author{
Ciro Aprea ${ }^{1}$, Adriana Greco $^{2}$, Angelo Maiorino ${ }^{1}$, Claudia Masselli $^{1^{*}}$ \\ ${ }^{1}$ DIIN, University of Salerno, Via Giovanni Paolo II 132, 84084, Fisciano (SA), Italy \\ ${ }^{2}$ DII, University of Naples "Federico II", P.le Tecchio 80, 80125, Naples, Italy \\ Email: cmasselli@unisa.it
}

\begin{abstract}
Electrocaloric and magnetic refrigeration are two emerging, solid-state based technology, which could constitute a real chance to overcome vapor compression refrigeration limits. To underline the differences and the affinities concerning such solid-state techniques, in this paper electrocaloric and magnetic refrigeration are compared through some performance parameters. For this purpose, it has been introduced a two-dimensional model, capable to reproduce, in room temperature range, the behaviors of both AMR and AER parallel plates regenerator. AMR and AER are the acronyms of Active Magnetic/Electrocaloric Regenerative cycle, respectively, which are inverse Brayton based thermodynamical cycles. In the model have been tested as refrigerant the most promising magnetic and electrocaloric materials, like $\mathrm{Gd}, \mathrm{Gd}_{5}\left(\mathrm{Si}_{\mathrm{x}} \mathrm{Ge}_{1-\mathrm{x}}\right)_{4}, \mathrm{LaFe}_{11.384}$ $\mathrm{Mn}_{0.356} \mathrm{Si}_{1.26} \mathrm{H}_{1.52}, \mathrm{LaFe}_{11.05} \mathrm{Co}_{0.94} \mathrm{Si}_{1.10}$, as magnetocaloric, P(VDF-TrFE-CFE)/BSTs, 0.93PMN-0.07PT, PLZTs, as electrocaloric ones. Among them, the PLZT thin film class confers the best results, higher than every magnetocaloric material tested, conferring to electrocaloric refrigeration the real role of the environmental friendly technology of the future.
\end{abstract}

Keywords: Electrocaloric Refrigeration, AER, Magnetic Refrigeration, AMR, FOT Materials, SOT Materials.

\section{INTRODUCTION}

On the world stage it has been estimated that refrigeration and air conditioning provoke $17 \%$ of energy consumption. The technology main responsible of such data is vapour compression (VC) since most of the refrigeration systems is based on. The refrigerants employed in $\mathrm{VC}$ have been multiple: from CFCs and HCFCs, interdicted by the Montreal Protocol [1] because of their capability to deplete the stratospheric ozone level (ODP, Ozone Depletion Potential), onward HFCs, without ODP but with a significant GWP (Global Warming Potential), whom are actually the only fluorinated fluids avoided. As a matter of fact, even if nowadays the contribution consists of $1 \%$ of all over the world greenhouse gases ones, HFC's emission are growing by 8-9\% annually [2]. With the Kyoto Protocol [3] and therefore with the consequent national laws and regulations, more stringent goals in the reduction of greenhouse gas emissions have been established, all having as common denominator the HFC consumption's phasing out [4]. Therefore, attention is now paid to the non-vapour-compression technologies for refrigeration and air conditioning. Among these technologies, the solid state cooling methods promise high systems efficiency [5]. A solid state material has no ODP and GWP because it does not disperse in the atmosphere. Solid state coolings are founded on the application of an external field. In particular, the application of a magnetic/electric field lies to a number of applications [6] related to refrigeration and fluid flow. Among them there are magnetic and electrocaloric refrigeration which the paper is focused on, that are two auspicious, unindustrialized technologies [7-10]. MagnetoCaloric Effect (MCE) [11] and Electro-Caloric Effect (ECE) are the physical phenomenon where, respectively, magnetic and electrocaloric refrigeration are based on. MCE has been revealed in material with magnetic properties, whereas ECE manifests itself in materials with dielectric properties. MCE and ECE derive from a connection between the material's entropy and a variable external field applied, since the orientation of its magnetic moments/electric dipole is a function of the verso of the magnetic/electric field. If the external field changes its intensity in an adiabatic process, an adiabatic change of the material's temperature is registered $\left(\Delta \mathrm{T}_{\mathrm{ad}}\right)$. Consequentially, an adiabatic magnetization/ polarization produces a decrease of magnetic/electric entropy contribution, while the total entropy has left constant, resulting in the growing of lattice and electro entropy terms; this lead to a rising of material's temperature. Dually the temperature is falling if the material is subjected to adiabatic demagnetization/depolarization. In MMs/EMs $\Delta \mathrm{T}_{\mathrm{ad}}$ is maximum in correspondence of Curie temperature, where the 
magnetic/electric phase transition takes place, whom could be FOT (First Order Transition) or SOT (Second Order Transition). A transition is classified as: first order if a discontinuity is registered in magnetization/polarization function; second order if magnetization/polarization is continuous whereas its derivative, the susceptibility, is discontinuous.

Considering an internally reversible process, the $\mathrm{MCE} / \mathrm{ECE}$ in term of $\Delta \mathrm{T}_{\mathrm{ad}}$ is:

$$
\begin{aligned}
& \left(\Delta \mathrm{T}_{\mathrm{ad}}\right)_{\mathrm{MC}}=-\mu_{\mathrm{o}} \int_{\mathrm{H}_{\mathrm{i}}}^{\mathrm{H}_{\mathrm{f}}} \frac{\mathrm{T}}{\mathrm{C}_{\mathrm{H}}}\left(\frac{\partial \mathrm{M}}{\partial \mathrm{T}}\right)_{\mathrm{H}} \mathrm{dH} \\
& \left(\Delta \mathrm{T}_{\mathrm{ad}}\right)_{\mathrm{EC}}=-\int_{\mathrm{E}_{\mathrm{i}}}^{\mathrm{E}_{\mathrm{f}}} \frac{\mathrm{T}}{\mathrm{C}_{\mathrm{E}}}\left(\frac{\partial \mathrm{P}}{\partial \mathrm{T}}\right)_{\mathrm{E}} \mathrm{dE} \\
& C_{H}=T\left(\frac{\delta s}{\delta T}\right)_{H} \\
& C_{E}=T\left(\frac{\delta s}{\Delta T}\right)_{E}
\end{aligned}
$$

Theoretical studies show that magnetic refrigeration has the potential to exhibit high cooling efficiencies $(30-60 \%$ of Carnot COP) [12]. The disadvantages of this technology reside in the high costs associated with the magnetic field generation and the magnetic materials. The first disadvantage of this technology lies in the difficulty of producing inexpensively and small-sized sufficient large magnetic field. For energy saving, the magnetic field can be generated by a permanent magnet, but the upper limit of the magnetic field induction that can be reached is around $1.8 \mathrm{~T}$. This limit can be achieved using $\mathrm{NdFeB}$ permanent magnets in Halbach array configuration, but it is very difficult to realize a miniaturized refrigerator. Another issue with this technology is that most of the magnetic materials are very expensive and has low availability since it belongs to the family of rare earth. The major advantage of the electrocaloric over magnetic refrigeration is represented by the greater easiness and lower expensiveness in reaching high electric fields required for ECE than magnetic fields. An electrocaloric cooling device can apply a large variable electric field by basically charging and discharging an EM capacitor. Furthermore, a COP of about $50 \%$ of the Carnot limit can be reached with electrocaloric refrigeration in small scale applications $[13,14]$.

In this paper is presented a collection of test performed on MMs and EMs, with a 2D model of AMR/AER [15-23] regenerator, in the same operating conditions and room temperature range, to make a comparison between magnetic and electrocaloric refrigeration.

\section{THE MOST PROMISING MAGNETOCALORIC \& ELECTROCALORIC MATERIALS}

In the general framework of materials to be considered possible candidates to solid state refrigeration, in this paper, it have been selected two subgroups: one for magnetic refrigeration, one for electrocaloric refrigeration. In the former subgroup, gadolinium (Gd) has for sure to be taken in consideration since, starting from the beginning of the diffusion of magnetic refrigeration, it has been considering the benchmark material of such technique. Belonging to the lanthanide group, gadolinium is a rare-earth element which shows a MCE maximum at 294K, where the SOT (ferromagnetic to paramagnetic) takes place [24-30]. Over the years, Pecharsky et al. demonstrated [31-33] that $\mathrm{Gd}_{5}\left(\mathrm{Si}_{1}\right.$ $\left.{ }_{x} \mathrm{Ge}_{\mathrm{x}}\right)_{4}(0<\mathrm{x}<0.5)$ compounds, which have phase transitions in the range of room temperatures, could exhibit greater values of MCE than the gadolinium itself, through FOT. Among them, $\mathrm{Gd}_{5} \mathrm{Si}_{2} \mathrm{Ge}_{2}$ is the material which has the highest MCE, called GIANT magnetocaloric effect, whose absolute maximum is located at $276 \mathrm{~K}$ (FOT), whereas a SOT is registered at $299 \mathrm{~K} . \mathrm{Gd}_{5} \mathrm{Si}_{2} \mathrm{Ge}_{2}$ may be considered a moderate hysteretic material $(2 \mathrm{~K})$. In the rare-earth scenario, there are also the rare-earth transition-metal $\mathrm{La}\left(\mathrm{Fe}_{\mathrm{x}} \mathrm{Si}_{1-\mathrm{x}}\right)_{13}$ compounds. Noteworthy because they exhibit a great $\operatorname{MCE}\left(\Delta \mathrm{S}_{\mathrm{T}}\right.$ of up to $30 \mathrm{~J} / \mathrm{kgK}$ under a $0-5 \mathrm{~T}$ magnetic field induction change), besides are cheap, widely disseminated and easily achievable, even if a modest hysteresis is registered together with $1 \%$ of volume variation. They are cubic materials: presenting a firstorder itinerant electron metamagnetic transition, with a giant magnetocaloric effect, but without structural modifications around the Curie temperature. To minimize the hysteresis (lower than $0.2 \mathrm{~K}$ ) and at the same time to shift the Curie temperature at room temperature, $\mathrm{La}\left(\mathrm{Fe}_{\mathrm{x}} \mathrm{Si}_{1-\mathrm{x}}\right)_{13}$ compounds are usually doped with atoms of $\mathrm{Mn}$ or Co [34]. The materials selected to be object of study of this paper are $\mathrm{LaFe}_{11.384}$ $\mathrm{Mn}_{0.356} \mathrm{Si}_{1.26} \mathrm{H}_{1.52}$ [35] and $\mathrm{LaFe}_{11.05} \mathrm{Co}_{0.94} \mathrm{Si}_{1.10}$ [36], which exhibit a FOT at $290 \mathrm{~K}$ and $287 \mathrm{~K}$, respectively. The subgroup of materials selected in such study for electrocaloric refrigeration embraces both bulk (single-crystals and ceramics) and films (polymers and ceramics) materials. $\mathrm{P}(\mathrm{VDF}-\mathrm{TrFE}-\mathrm{CFE}) / \mathrm{BST}$ polymer nanocomposities [37,38] have been selected, for their high ECE, since they are made up of a polymer matrix of P(VDF-TrFE-CFE) 62.3/29.9/7.8 mol\% doped with $\left(\mathrm{Ba}_{\mathrm{x}} \mathrm{Sr}_{1-\mathrm{x}} \mathrm{TiO}_{3}\right)$, to reduce the ferroelectric domain size and the energy bandgap to phase transition. Thus, doping with $\mathrm{Ba}_{0.67} \mathrm{Sr}_{0.33} \mathrm{TiO}_{3}$ (BST67), $\mathrm{Ba}_{0.71} \mathrm{Sr}_{0.29} \mathrm{TiO}_{3}$ (BST71), $\mathrm{Ba}_{0.74} \mathrm{Sr}_{0.26} \mathrm{TiO}_{3}$ (BST74), $\mathrm{Ba}_{0.77} \mathrm{Sr}_{0.23} \mathrm{TiO}_{3}$ (BST77) increases the intensity of the electrical field induction $\mathrm{D}$ which carries to enhanced ECE with quite low electric field applied. Another material chosen for the paper's purposes is $0.93 \mathrm{PMN}-0.07 \mathrm{PT}$ thin film $[39,40]$ because of its giant ECE at $27^{\circ} \mathrm{C}$. It is made up of the $\mathrm{PbMg}_{2 / 3} \mathrm{Nb}_{1 / 3} \mathrm{O}_{3}$ relaxor ceramic, filled with $\mathrm{PbTiO} 3(\mathrm{PT})$, to achieve a wide-range of dipolar ordering. PLZT $\mathrm{Pb}_{1-3 \mathrm{x} / 2} \mathrm{La}_{\mathrm{x}} \mathrm{Zr}_{0.85} \mathrm{Ti}_{0.15} \mathrm{O}_{3}$ [41] thick films have been considered: worthy of consideration are the "up-graded" and the "down-graded" antiferroelectric compositions obtained, respectively, by increasing the La content from 8 to $14 \mathrm{~mol} \%$ and vice-versa, to improve many dielectric characteristics. Also, PLZT 11/85/15 in single composition has been tested. Thus a comparison could be done.

The cooling efficiency of a MM/EM can be evaluated considering the magnitude of $\Delta \mathrm{T}_{\mathrm{ad}}$ and a parameter called relative cooling power in an adiabatic process [42], RCP(T), and defined as:

$R C P(T)=\Delta T_{a d_{(\max )}} * \Delta T_{F W H M}$

All the features of the above-mentioned MMs and EMs are summed up in Table 1, where the reported values in $\Delta \mathrm{T}_{\mathrm{ad}}$ column are the peak ones. All the EMs show a thermal conductivity lower than MMs. Indeed, for EMs any increase in conductivity, either electronic or ionic, causes leakage current under the applied field, which results in Joule heating. PLZTs show peak values of $\Delta T_{a d}$ and $\operatorname{RCP}(T)$ always higher 
than the other materials. Among MMs, $\mathrm{Gd}_{5}\left(\mathrm{Si}_{\mathrm{x}} \mathrm{Ge}_{1-\mathrm{x}}\right)_{4}$ shows the higher $\Delta \mathrm{Tad}$ peak values, but out of the room temperature range. The best $\mathrm{RCP}(\mathrm{T})$ material, among MMs, are Gd and $\mathrm{Gd}_{5}\left(\mathrm{Si}_{\mathrm{x}} \mathrm{Ge}_{1-\mathrm{x}}\right)_{4}$ whose value are satisfactory.

Table 1. Characteristics of the magnetocaloric and electrocaloric materials in the room temperature range.

\begin{tabular}{|c|c|c|c|c|c|c|}
\hline Material & $\begin{array}{c}\mathrm{T}_{\mathrm{C}} \\
{[\mathrm{K}]}\end{array}$ & $\begin{array}{c}\Delta \mathrm{H} \text { or } \\
\Delta \mathrm{E} \\
{[\mathrm{T}][\mathrm{V} / \mathrm{m}]}\end{array}$ & $\begin{array}{c}\Delta \mathrm{T}_{\mathrm{ad}} \\
{[\mathrm{K}]}\end{array}$ & $\begin{array}{c}\rho \\
{\left[\mathrm{kg} / \mathrm{m}^{3}\right]}\end{array}$ & $\begin{array}{c}\mathrm{k} \\
{[\mathrm{W} / \mathrm{mK}]}\end{array}$ & $\begin{array}{c}\mathrm{RCP}(\mathrm{T}) \\
{\left[\mathrm{K}^{2}\right]}\end{array}$ \\
\hline $\begin{array}{l}\mathrm{P}(\mathrm{VDF}-\mathrm{Tr} \\
\text { FE-CFE) } \\
\text { /BST67 }\end{array}$ & 311 & 75 & 9.2 & 2060 & 1 & 1087 \\
\hline $\begin{array}{l}\text { P(VDF-Tr } \\
\text { FE-CFE)/ } \\
\text { BST71 }\end{array}$ & 322 & 75 & 9.4 & 2060 & 1 & 1038 \\
\hline $\begin{array}{l}\text { P(VDF-Tr } \\
\text { FE-CFE)/ } \\
\text { BST74 }\end{array}$ & 331 & 75 & 9.7 & 2060 & 1 & 1019 \\
\hline $\begin{array}{l}\text { P(VDF-Tr } \\
\text { FE-CFE)/ } \\
\text { BST77 }\end{array}$ & 337 & 75 & 9.9 & 2060 & 1 & 960 \\
\hline $\begin{array}{l}0.93 \mathrm{PMN}- \\
0.07 \mathrm{PT}\end{array}$ & 298 & 50.9 & 9 & 8300 & 1.384 & 125 \\
\hline $\begin{array}{l}0.93 \mathrm{PMN}- \\
0.07 \mathrm{PT}\end{array}$ & 298 & 72.3 & 13 & 8300 & 1.384 & 160 \\
\hline $\begin{array}{l}\text { PLZT } \\
\text { upgraded }\end{array}$ & / & 90 & 28 & 7900 & 1.9 & 2800 \\
\hline $\begin{array}{l}\text { PLZT } \\
\text { downgraded }\end{array}$ & / & 90 & 20 & 7900 & 1.9 & 1200 \\
\hline $\mathrm{Gd}$ & 294 & 1.5 & 6 & 7900 & 10.9 & 187 \\
\hline $\begin{array}{l}\mathrm{Gd}_{5}\left(\mathrm{Si}_{\mathrm{x}}\right. \\
\left.\mathrm{Ge}_{1-\mathrm{x}}\right)_{4}\end{array}$ & 276 & 1.5 & 14 & 7205 & 5.8 & 117 \\
\hline $\begin{array}{l}\mathrm{LaFe}_{11.384} \\
\mathrm{Mn}_{0.356} \\
\mathrm{Si}_{1.26 \mathrm{H}_{1.52}}\end{array}$ & 290 & 1.5 & 5 & 7100 & 9 & 50 \\
\hline $\begin{array}{l}\mathrm{LaFe}_{11.05} \\
\mathrm{Co} 0.94 \mathrm{Si}_{1.10}\end{array}$ & 287 & 1.5 & 5.5 & 7290 & 8.9 & 30 \\
\hline $\begin{array}{l}\mathrm{MnFeP}_{0.45} \\
\text { As } 0.55\end{array}$ & 307 & 1.5 & 4 & 7300 & 2.5 & 470 \\
\hline
\end{tabular}

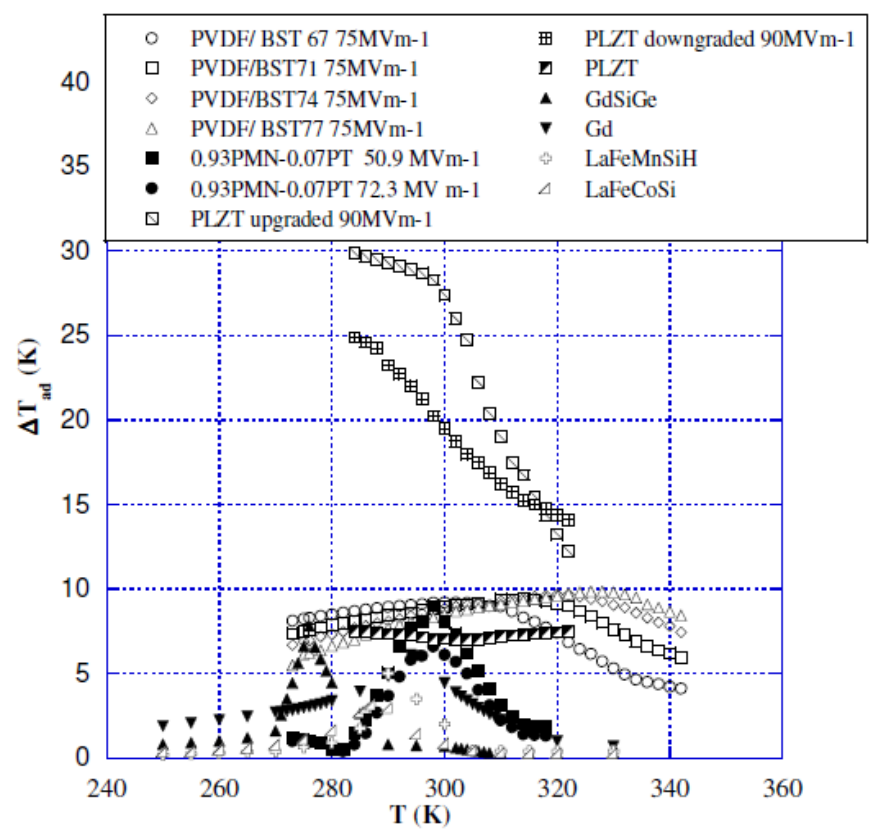

Figure 1. $\Delta \mathrm{T}_{\text {ad }}$ as a function of temperature for the presented magnetocaloric and electrocaloric materials

Figure 1, in which one can appreciate the $\Delta \mathrm{T}_{\mathrm{ad}}(\mathrm{T})$ trends for all the MMs and EMs treated, clearly demonstrates that the PLZT compositionally graded structure exhibit the values of $\Delta \mathrm{T}_{\mathrm{ad}}$ in all the temperature range. Also $\mathrm{P}(\mathrm{VDF}-\mathrm{TrFE}-\mathrm{CFE})$ /BST polymer nanocomposities exhibit appreciable values in terms of $\Delta \mathrm{T}_{\mathrm{ad}}$ whereas, among MMs, $\mathrm{Gd}_{5}\left(\mathrm{Si}_{\mathrm{x}} \mathrm{Ge}_{1-\mathrm{x}}\right)_{4}$ shows the highest values but very temperature confined. Gd, the benchmark material of magnetic refrigeration, shows quite smaller values of $\Delta \mathrm{T}_{\mathrm{ad}}$ but remarkable over a more extensive range.

The objective of this paper is to present a comparison between electrocaloric and magnetocaloric refrigeration, considering the most significant parameters of performance (temperature span, COP and cooling power), through the simulation performed on the 2D model of AER/AMR, which replicate the thermo-fluidodynamic behavior of solid state refrigerating systems. As refrigerants have been tested all the EMs and MMs introduced above: P(VDF-TrFE-CFE)/BSTs, 0.93PMN-0.07PT, PLZTs, Gd, $\mathrm{Gd}_{5}\left(\mathrm{Si}_{\mathrm{x}} \mathrm{Ge}_{1-\mathrm{x}}\right)_{4}, \mathrm{LaFe}_{11.384}$ $\mathrm{Mn}_{0.356} \mathrm{Si}_{1.26} \mathrm{H}_{1.52}, \mathrm{LaFe}_{11.05} \mathrm{Co}_{0.94} \mathrm{Si}_{1.10}$.

\section{CALORIC REFRIGERATION}

Magnetic and electrocaloric refrigeration are both reverse Brayton cycle based, whom its principle of operation is reported on an S-T diagram shown in Figure 2 (right side). It is composed by two adiabatic and two isofield processes. By magnetization/polarization (1-2) the solid state refrigerant increases its temperature. This process is analogous to the compression one in Vapour-Compression Refrigeration (VCR). In the stage (2-3) the heat generated, due to caloric effect, is rejected through a heat transfer toward a heat sink. This stage in analogous to condensation in VCR. In the stage (3-4), analogous to the expansion one in VCR, the field is removed and therefore the material cools down thanks to $\mathrm{MCE} / \mathrm{ECE}$. In the fourth stage (4-1), which is analogous to evaporation in VCR, the solid state material, which currently is cold, absorb heat from cold reservoirs and recovers the initial state [43]. An inverse Brayton cycle, referred to magnetic/electrocaloric refrigeration, if the solid state material (MM/EM) plays both the refrigerating and regenerator role, evolves in Active Magnetic/Electrocaloric Regenerative cycle (AMR/AER). In AMR/AER cycle a secondary fluid (water) is introduced as a heat transfer vector, flowing throughout the MM/EM regenerator.

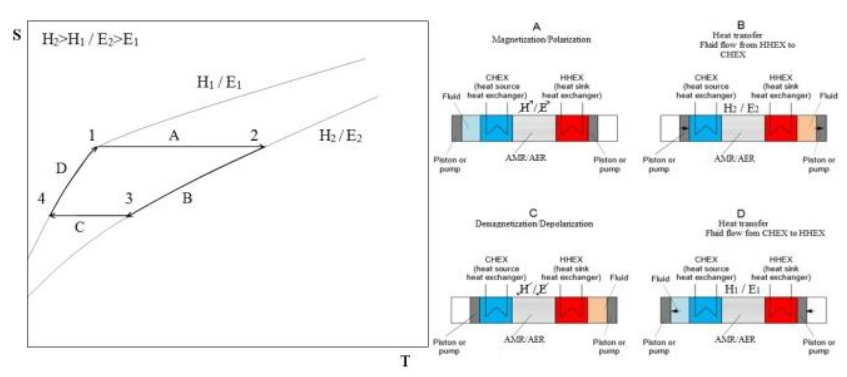

Figure 2. MCE/ECE reverse Brayton regenerative cycle on an S-T diagram (a). The AMR/AER cycle (b)

The working principle of AMR/AER cycle is shown on the left side of Figure 2. During magnetization/polarization (A) the field is increased by the maximum value, while the fluid is not flowing, causing the increasing of the material's temperature, due to $\mathrm{MCE} / \mathrm{ECE}$. In the second stage (B), the field remains constant and the cold fluid crosses the AMR/AER from the cold to the hot side, thus cooling the regenerator and rejecting heat in the hot heat exchanger. 
When in the third stage (C) the field is removed, while the fluid hasn't any motion, the regenerator sees another decrement in its temperature, thanks to MCE/ECE. As a final stage (D), while the field is absent, the fluid flows across the regenerator from the hot to cold side, cooling itself and then reaching the cold heat exchanger, where it absorbs heat from the latter, producing a cooling load.

Figure 3 shows a schematic illustration of the AMR/AER geometry considered: a displacer (or in other cases a variable speed pump) drives the secondary fluid circulations through the regenerator bed alternatively from the cold end to the hot end and vice versa. A group of valves could be employed as controller of the direction of the fluid flows.

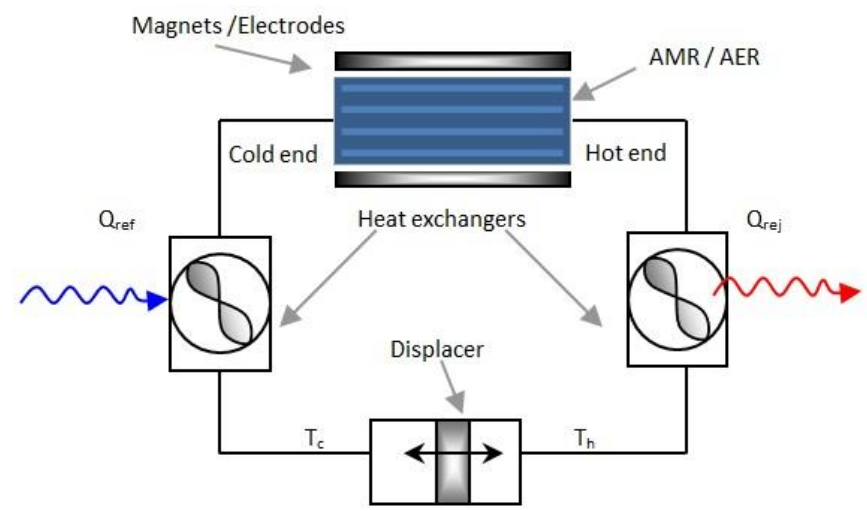

Figure 3. Sketch of the AMR/AER equipped with the heat exchanger and the displacer

\section{MODEL DESCRIPTION}

\subsection{Regenerator geometry}

All the materials have been tested through simulations done on a $2 \mathrm{D}$ numerical model of AMR/AER parallel plates regenerator, operating at room temperature. The maximum field induction considered are: $1.5 \mathrm{~T}$ for magnetic one, which constitute an upper limit, obtained experimentally with permanent magnets, placed in a Halbach array configuration. For the AER cycle the performances have been evaluated for different electric fields, by varying the intensity from 0 to 90 $\mathrm{MVm}^{-1}$. In all the simulations carried out the cycle frequency is $1.25 \mathrm{~Hz}$, selected since it optimizes [44] the cycle performances. Indeed, a preliminary campaign by numerical simulation has been carried out to identify the optimal cycle frequency. The secondary fluid is deionized water that flows in the channels between the plates [45-49].

The model replies the behavior of an AMR/AER regenerator in parallel plates configuration. Every plate has the same thickness $(0.25 \mathrm{~mm})$ and the distance stacked between each other is 0.125 , which also corresponds to each fluid channel thickness. The wrapper which contains the regenerator occupies a $20 \times 45 \mathrm{~mm}^{2}$ area, whom is occupied globally for $60 \%$ from the parallel plates made of MM/EM. To choose a value of thickness right for all the materials considered, the thermal penetration depth, has been taken in consideration, according to the following formula [50]:

$$
\delta=\sqrt{\frac{k}{\pi f \rho c}}
$$

Table 2 contains all the penetration depths evaluated for the materials under test (both MMs and EMs), according to the operational AMR/AER frequency, to demonstrate that $0.25 \mathrm{~mm}$, the thickness chosen for the plates, is smaller than every $\delta$. Moreover, $0.25 \mathrm{~mm}$ is the right value since, not only it is enough small for $\delta$, but at the same time it is enough large to not produce too much heaviness to the computational time. Moreover, it is observable that, among all the tested materials, MMs present always $\delta$ higher than EMs. Indeed, the EMs are characterized by lower values of thermal conductivities despite to MMs because this leads to smaller leakage currents. Leakage currents are strictly related to Joule heating, an undesired effect in AMR/AER operations.

Table 2. Thermal penetration depth for the presented materials.

\begin{tabular}{lclc}
\hline Material & $\begin{array}{c}\delta \\
{[\mathrm{mm}]}\end{array}$ & Material & $\begin{array}{c}\delta \\
{[\mathrm{mm}]}\end{array}$ \\
\hline $\begin{array}{l}\text { P(VDF-TrFE- } \\
\text { CFE)/BSTs }\end{array}$ & 0.31 & $\mathrm{Gd}$ & 1.12 \\
\hline 0.93 PMN-0.07PT & 0.36 & $\mathrm{Gd}_{5}\left(\mathrm{Si}_{\mathrm{x}} \mathrm{Ge}_{1-}\right)_{4}$ & 0.83 \\
\hline PLZT11/85/15 & 0.38 & $\mathrm{LaFe}_{11.384} \mathrm{Mn}_{0.356}$ & 0.68 \\
\hline PLZT upgraded & 0.38 & $\mathrm{LaFe}_{11.05} \mathrm{Co}_{0.94} \mathrm{Si}_{1.10}$ & 0.75 \\
\hline PLZT downgraded & 0.38 & Deionized water & 0.19 \\
\hline
\end{tabular}

The simulations have been carried out, bearing in mind of the succeeding reported hypothesis:

(1) absence of Eddy currents and negligible Joule heating;

(2) neglecting of heat radiation and thermal hysteresis;

(3) adiabatic regenerator with infinite heat exchange area.

\subsection{Mathematical formulation}

To describe accurately, the regenerator's behavior by a mathematical model, is appropriate to specify that each of the four AMR/AER processes is modeled by a different set of equations. The fluid flow processes are governed by the Navier-Stokes and the solid and fluid energy equations, to be aware of the temperatures and fluid velocity, as follows:

$$
\left\{\begin{array}{c}
\frac{\partial u}{\partial x}+\frac{\partial v}{\partial y}=0 \\
\frac{\partial u}{\partial t}+u \frac{\partial u}{\partial x}+v \frac{\partial u}{\partial y}=-\frac{1}{\rho_{f}} \frac{\partial p}{\partial x}+v\left(\frac{\partial^{2} u}{\partial x^{2}}+\frac{\partial^{2} u}{\partial y^{2}}\right) \\
\frac{\partial v}{\partial t}+u \frac{\partial v}{\partial x}+v \frac{\partial v}{\partial y}=-\frac{1}{\rho_{f}} \frac{\partial p}{\partial y}+v\left(\frac{\partial^{2} v}{\partial x^{2}}+\frac{\partial^{2} v}{\partial y^{2}}\right) \\
\frac{\partial T_{f}}{\partial t}+u \frac{\partial T_{f}}{\partial x}+v \frac{\partial T_{f}}{\partial y}=\frac{k_{f}}{\rho_{f} C_{f}}\left(\frac{\partial^{2} T_{f}}{\partial x^{2}}+\frac{\partial^{2} T_{f}}{\partial y^{2}}\right) \\
\frac{\partial T_{x}}{\partial t}=\frac{k_{s}}{\rho_{s} C}\left(\frac{\partial^{2} T_{s}}{\partial x^{2}}+\frac{\partial^{2} T_{s}}{\partial y^{2}}\right)
\end{array}\right.
$$

where it has been assumed that the fluid is incompressible and laminar and, because of the low mass flow, the viscous dissipation is neglected.

Magnetization/demagnetization-polarization/depolarization processes are regulated by the energy equations. In the solid equation there is an heat source term $\mathrm{Q}$, which models the MCE/ECE. It depends on the intensity of the applied external field and it is proportional to $\Delta \mathrm{T}_{\mathrm{ad}}$ as follows:

$Q=Q\left(\right.$ field,$\left.T_{S}\right)=\frac{\rho_{s} C\left(\text { field } T_{s}\right) \Delta T_{a d}\left(\text { field }{ }_{u} T_{S}\right)}{\tau}$

where $\tau$ is the time period of each process. 
$\mathrm{W} / \mathrm{m}^{3}$ is the unit of $\mathrm{Q}$, since it is a power density, which is positive during magnetization/polarization, negative during demagnetization/depolarization processes. Thus the equations are:

$$
\left\{\begin{array}{c}
\rho_{f} C_{f} \frac{\partial T_{f}}{\partial t}=k_{f}\left(\frac{\partial^{2} T_{f}}{\partial x^{2}}+\frac{\partial^{2} T_{f}}{\partial y^{2}}\right) \\
\rho_{g} C \frac{\partial T_{s}}{\partial t}=k_{g}\left(\frac{\partial^{2} T_{s}}{\partial x^{2}}+\frac{\partial^{2} T_{s}}{\partial y^{2}}\right)+Q
\end{array}\right.
$$

By an elaboration of experimental data of $\mathrm{C}(\mathrm{B} / \mathrm{E}, \mathrm{T})$ $\Delta \mathrm{T}_{\mathrm{ad}}(\mathrm{B} / \mathrm{E}, \mathrm{T})$, available from literature, it has been built the functions of $\mathrm{Q}(\mathrm{B} / \mathrm{E}, \mathrm{T})$. The corresponding mathematical expressions of $\mathrm{Q}$ for magnetization/polarization and demagnetization/depolarization processes, for every MM/EM under test, have been obtained through an analytical function finder software.

By the way, the AMR/AER behaviors for every MMs/ EMs, have been obtained by solving the mathematical systems (eq. (7) and (9)) that rule AMR/AER cycles, using Finite Element Method. The cycle is conceived as a succession of sequential stages: the initial conditions of one of them are the results of the previous one. Every stage has a period $\tau$ which is the same during all the processes of the AMR/AER cycle. The presence of heat exchangers, during fluid flow phases, are obtained applying first order boundary conditions: $\mathrm{T}_{\mathrm{C}}$ and $\mathrm{T}_{\mathrm{H}}$, the temperature of the cold and hot heat exchanger, on the left and right boundary, respectively, of the AMR/AER regenerator. The simulations are done, repeating AMR/AER cycle a number of time with constant frequency, until reaching the steady state.

The cooling power and the power related to the heat supplied in the environment are calculated as:

$$
\begin{aligned}
& \phi_{\text {ref }}=\frac{1}{4 \pi} \int_{a \tau}^{4 \pi} \dot{m}_{f} C_{f}\left(T_{C}-T_{f}(0, y, t)\right) d t \\
& \phi_{\text {rej }}=\frac{1}{4 \pi} \int_{\tau}^{2 \pi} \dot{m}_{f} C_{f}\left(T_{f}\left(L_{s} y, t\right)-T_{H}\right) d t
\end{aligned}
$$

The mechanical power associated with the circulation pump is:

$$
W_{p}=\frac{m\left(\Delta p_{C F}+\Delta p_{H F}\right)}{m_{P} P_{f}}\left(t_{C F}+t_{H F}\right)
$$

The Coefficient of Performance has been introduced to estimate the performance of the two models as follows:

$$
\operatorname{COP}=\frac{Q_{r v f}}{Q_{H}-Q_{r v f}+W_{D}}
$$

The $\Delta \mathrm{T}_{\text {span }}$, obtained by evaluating the difference between $\mathrm{T}_{\mathrm{H}}$ and the cold side temperature of the secondary fluid averaged in the last process of the AMR/AER cycle (fluid flow from hot to cold side of the regenerator), is evaluated as in the following equation:

$$
\Delta T_{\text {gpan }}=T_{H}-\int_{a \pi}^{4 \pi} T_{f}(0, y, t) d t
$$

\subsection{Validation of the model}

The two-dimensional numerical model introduced in this paper has been validated through a comparison between the result collected and experimental ones, obtained by carrying out the results from a Rotary Permanent Magnet Magnetic
Refrigerator (RPMMR), developed at the Refrigeration Lab (LTF), University of Salerno [44,46-49]. RPMMR is the first Italian prototype of magnetic refrigerator: it is composed by 8 regenerators, fixed radially in a stationary ring, whom is subjected to a variable magnetic field, generated by the rotation of permanent magnets. Each regenerator is made of gadolinium, employed as refrigerant, for a total mass of 1.20 $\mathrm{kg}$ in the whole device, whereas distilled water covers the role of secondary fluid. The geometry of the regenerator presented in this model corresponds to one of a single regenerator of the RPMMR along a longitudinal section, with respect of the fluid flowing. The model exhibits a general behavior in overestimating experimental data: it is as more relevant as the greater is $T_{\mathrm{H}}$. A possible explanation of this effect could reside in heat leakages toward the environment caused by a defective thermal insulation. The overestimation goes from a minimum value of 0 to a maximum of $+20 \%$.

\section{RESULTS}

Some AMR/AER cycles have been replicated to make the proposed comparison between the presented MMs and EMs. The materials candidate for the tests are the ones listed in Table 1. The performances of the first group have been estimated for a maximum magnetic field induction of $1.5 \mathrm{~T}$. The second group has been working under different electric fields, whose intensity sweeps from 0 to $90 \mathrm{MV} / \mathrm{m}$, but always remaining under the breakdown values related to every EM. The operating AMR/AER cycle is constant at 1.25 $\mathrm{Hz}$, since it maximizes [44] the COP cycle, whereas three different fluid flow rate have been tested $(0.034,0.046,0.057$ $\mathrm{kg} / \mathrm{s})$. The tests have been carried out in two different $\mathrm{T}_{\mathrm{C}} \div \mathrm{T}_{\mathrm{H}}$ temperature ranges: $287 \div 295 \mathrm{~K}$ and $292 \div 300 \mathrm{~K}$.

Figures 4-5 report $\Delta \mathrm{T}_{\text {span, }}$, detected for all the different materials under the three fluid flow speeds investigated in the temperature range of $287 \div 295 \mathrm{~K}$. One can observe that the temperature span is as larger as smaller is the water mass flow rate; to this reason, a regeneration of the fluid allows touching smaller temperatures proper on the cold side. Moreover the greatest values of $\Delta \mathrm{T}_{\text {span }}$ are the compositionally graded $\mathrm{EM}$ structures ones. Indeed, the best value of $\Delta \mathrm{T}_{\text {span }}$ of single composition material doesn't exceed $13 \mathrm{~K}$ instead the best value of $\Delta \mathrm{T}_{\text {span }}$ of compositionally graded structure goes above $23 \mathrm{~K}$. An AER cycle working with the upgraded PLZT shows a $\Delta \mathrm{T}_{\text {span }}$ between 23 and $23.5 \mathrm{~K}$, whereas an AMR with the best MM (that is $\mathrm{Gd}_{5} \mathrm{Si}_{2} \mathrm{Ge}_{2}$ ) shows a $\Delta \mathrm{T}_{\text {span }}$ between 11 and $12.7 \mathrm{~K}$. Therefore AER $\Delta \mathrm{T}_{\text {span }}$ are $+85 \div+109 \%$ greater than AMR ones, equal to operating conditions. Among the single composition materials, the greatest $\Delta \mathrm{T}_{\text {span }}$ are $\mathrm{Gd}_{5} \mathrm{Si}_{2} \mathrm{Ge}_{2}$ and PLZT ones which are similar (between 11 and $12.6 \mathrm{~K}$ ). The benchmark material for magnetic refrigeration is $\mathrm{Gd}$, although its $\Delta \mathrm{T}_{\text {span }}$ values are lower than those of $\mathrm{Gd}_{5} \mathrm{Si}_{2} \mathrm{Ge}_{2}$ (from -35 to $-19 \%$ ).

In Figure 6 is reported the refrigerant power as a function of water flow rate for all the materials presented in this work (except for the compositionally graded PLZTs shown in Figure 7) in the temperature range of $287 \div 295 \mathrm{~K}$. The refrigerating power is higher as long as the greater is the water flow rate. The greater $\mathrm{Q}_{\text {ref }}$ values are proper of PLZT

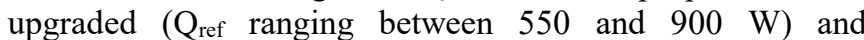
downgraded (higher than $470 \mathrm{~W}$ ) structures. Acceptable values (confined in $150 \div 220 \mathrm{~W}$ ) are exhibited by PVDF/BST polymer nanocomposities and PLZT with a single composition. The best $\mathrm{MM}$ is $\mathrm{Gd}_{5} \mathrm{~S}_{\mathrm{i} 2} \mathrm{Ge}_{2}$ although its $\mathrm{Q}_{\text {ref }}$ 
values are lower than PLZT single composition (from -33\% to $-28 \%$ ).

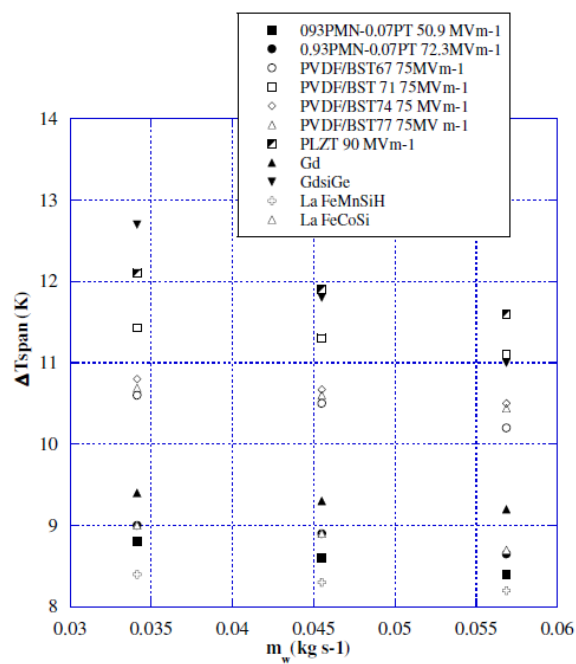

Figure 4. $\Delta \mathrm{T}_{\text {span }}$ evaluated for different materials with respect to fluid flow rate in the $287 \div 295 \mathrm{~K}$ temperature range

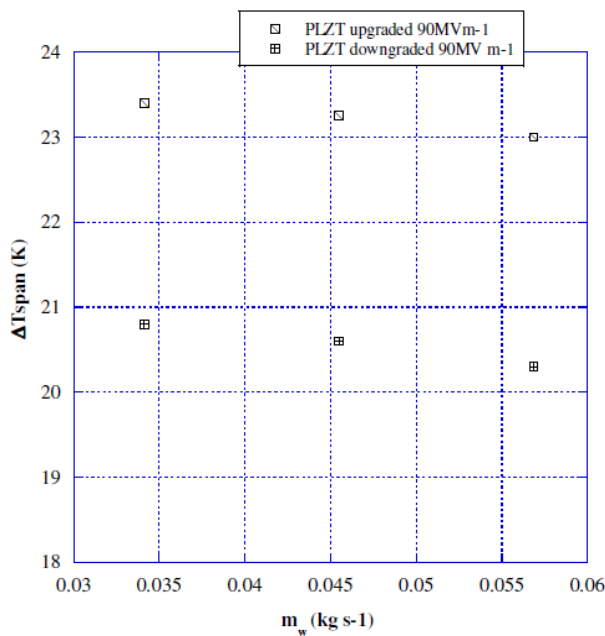

Figure 5. $\Delta \mathrm{T}_{\text {span }}$ evaluated for compositionally graded PLZT EMs with respect to fluid flow rate in the $287 \div 295 \mathrm{~K}$ temperature range

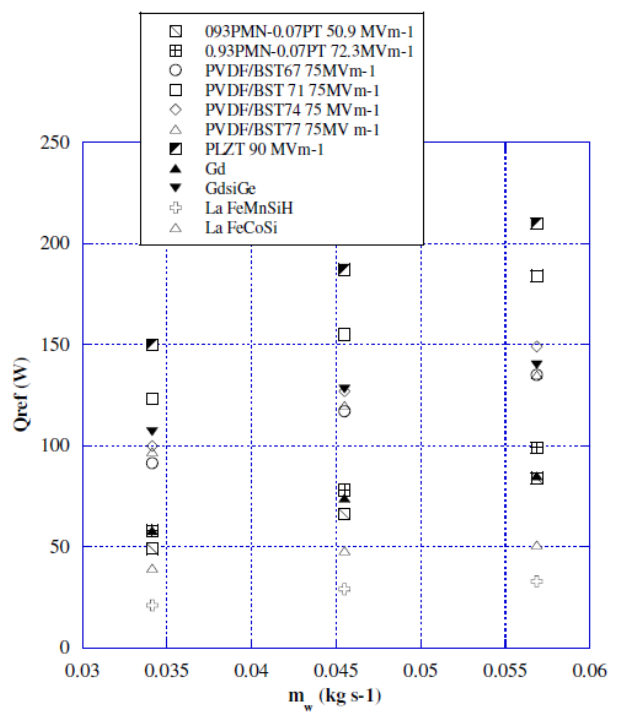

Figure 6. $\mathrm{Q}_{\text {ref }}$ evaluated for different materials with respect to fluid flow rate in the $287 \div 295 \mathrm{~K}$ temperature range

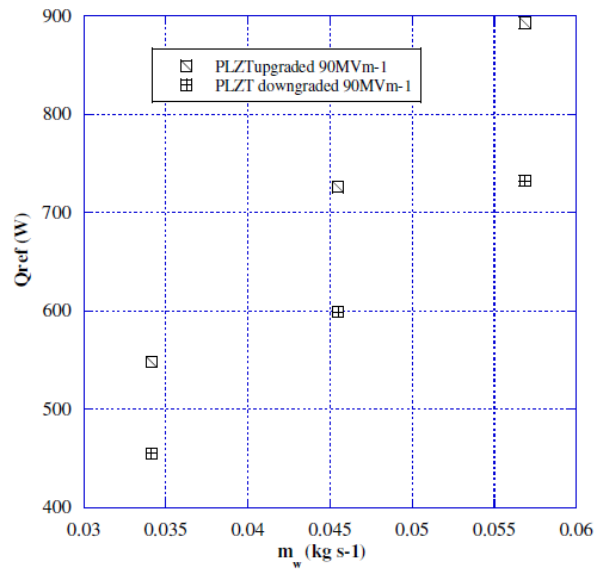

Figure 7. $\mathrm{Q}_{\text {ref }}$ evaluated for compositionally graded PLZT EMs with respect to fluid flow rate in the $287 \div 295 \mathrm{~K}$ temperature range

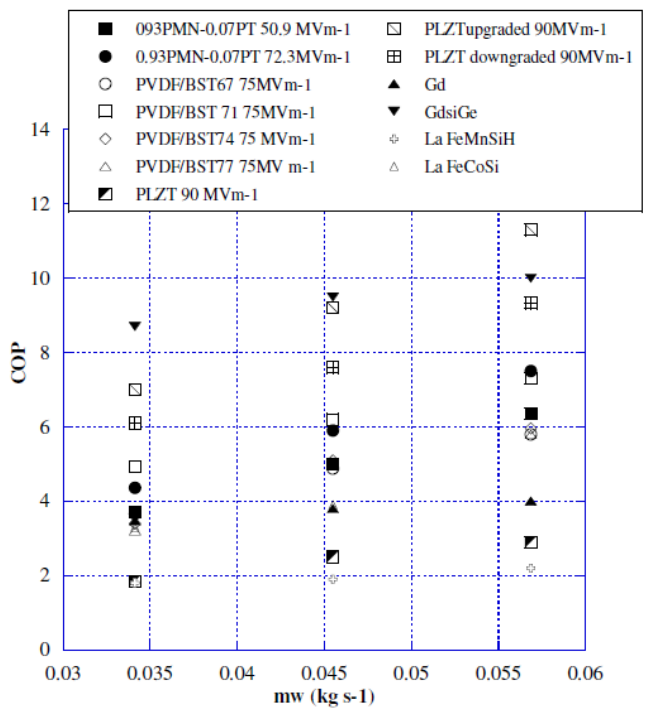

Figure 8. COP evaluated for different materials with respect to fluid flow rate in the $287 \div 295 \mathrm{~K}$ temperature range

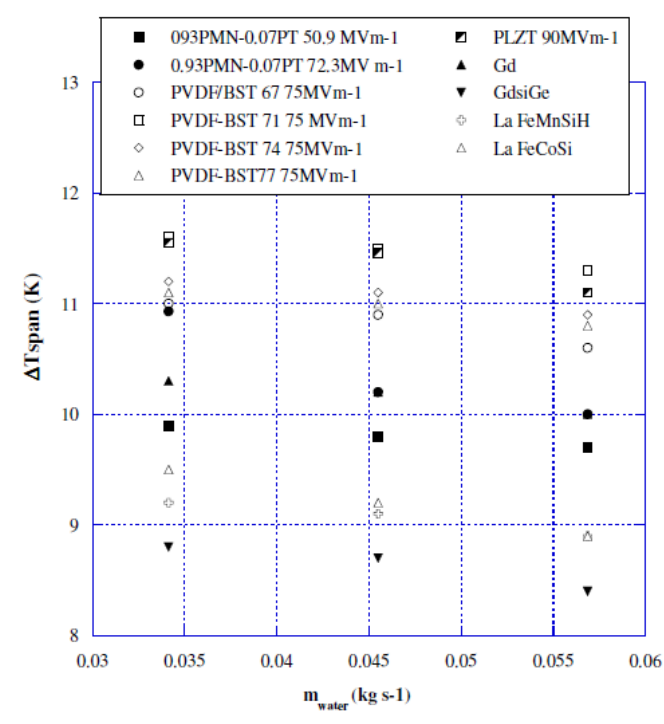

Figure 9. $\Delta \mathrm{T}_{\mathrm{span}}$ evaluated for different materials with respect to fluid flow rate in the $292 \div 300 \mathrm{~K}$ temperature range 


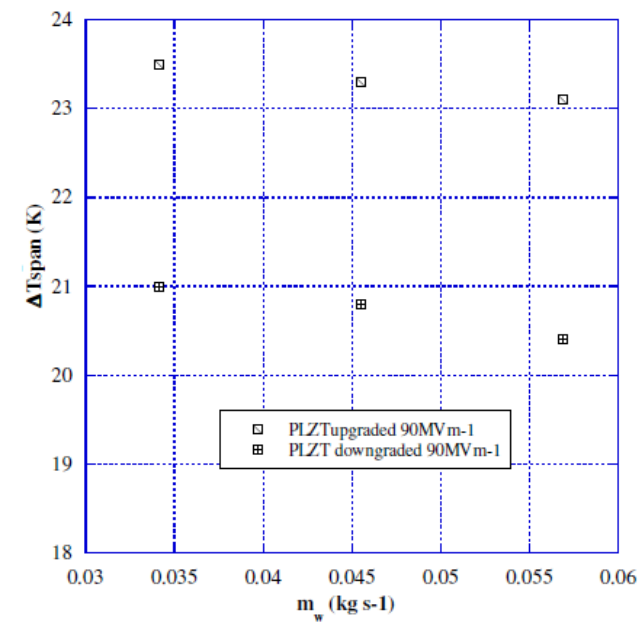

Figure 10. $\Delta \mathrm{T}_{\text {span }}$ evaluated for compositionally graded PLZT EMs with respect to fluid flow rate in the $292 \div 300 \mathrm{~K}$ temperature range

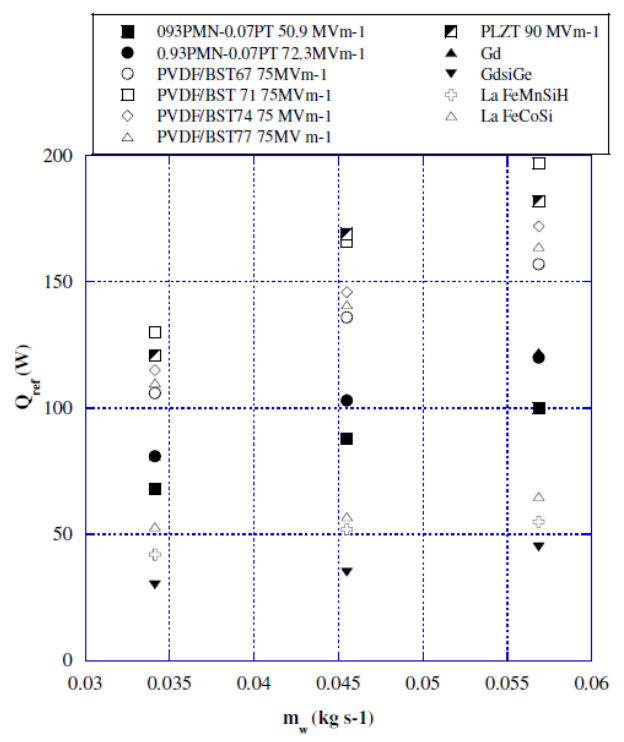

Figure 11. $Q_{\text {ref }}$ evaluated for different materials with respect to flow rate in the $292 \div 300 \mathrm{~K}$ temperature range

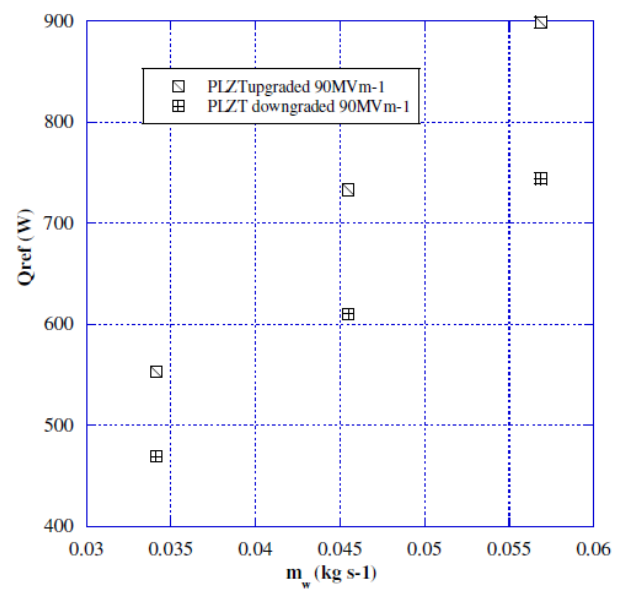

Figure 12. $\mathrm{Q}_{\text {ref }}$ evaluated for compositionally graded PLZT EMs with respect to fluid flow rate in the $292 \div 300 \mathrm{~K}$ temperature range
Figure 8 illustrates the Coefficient of Performance (COP) evaluated for all the materials presented in this work in the temperature range of $287 \div 295 \mathrm{~K}$. As the refrigerant power, COP increases according to the increase of the water flow rate too. The highest values of COP have been estimated for PLZT with the upgraded composition (between 7 and 11.3) and $\mathrm{Gd}_{5} \mathrm{Si}_{2} \mathrm{Ge}_{2}$ (between 8.7 and 10) but with a lower refrigerant power (ranging between 107 and 140W) suitable for small-scale applications. PLZT materials show a great electric power due to a low electrical resistivity.

A second campaign of simulations has been carried out in the temperature range $292 \div 300 \mathrm{~K}$. The results clearly show that the temperature range varying strongly affects the behaviour of the MM materials, whereas the EM are poorly influenced. Indeed, the EMs show appreciable values of ECE in a wide temperature range, whereas the MMs show appreciable values of $\mathrm{MCE}$ in a much more confined temperature range centring their Curie temperatures. In Figures 9 and 10 one can see $\Delta \mathrm{T}_{\text {span }}$ measured for the tested materials for all the fluid flow speed under test. In these simulations, $\Delta \mathrm{T}_{\text {span }}$ values of $\mathrm{Gd}_{5} \mathrm{Si}_{2} \mathrm{Ge}_{2}$ show a significant reduction, whereas a remarkable increase is registered in those of $\mathrm{Gd}$. The latest results are due to the chosen temperature range, whom is centred around the Curie temperature of $\mathrm{Gd}$, whereas is far from the Curie temperature of $\mathrm{Gd}_{5} \mathrm{Si}_{2} \mathrm{Ge}_{2}$. In this temperature range the best $\mathrm{MM}$ is $\mathrm{Gd}$, although its $\Delta \mathrm{T}_{\text {span }}$ values are significantly lower than that of PVDF/BST polymer nanocomposities (around -11\%) and PLZT with a single composition (around -12\%). The worst material is $\mathrm{Gd}_{5} \mathrm{Si}_{2} \mathrm{Ge}_{2}$.

Figures 11 and 12 illustrate Qref as a function of the water flow speed. The refrigerant power of $\mathrm{Gd}$ is lower than PVDF/BST polymer nanocomposities (around -51\%) and PLZT with a single composition (around -49\%).

In Figure 13 are reported the COP values for the different materials. The highest values of COP have been estimated for PLZT with the upgraded composition (between 6.9 and 11.2) and Gd (between 6.2 and 9) but with a lower refrigerant power (between -350 and $-390 \%$ ).

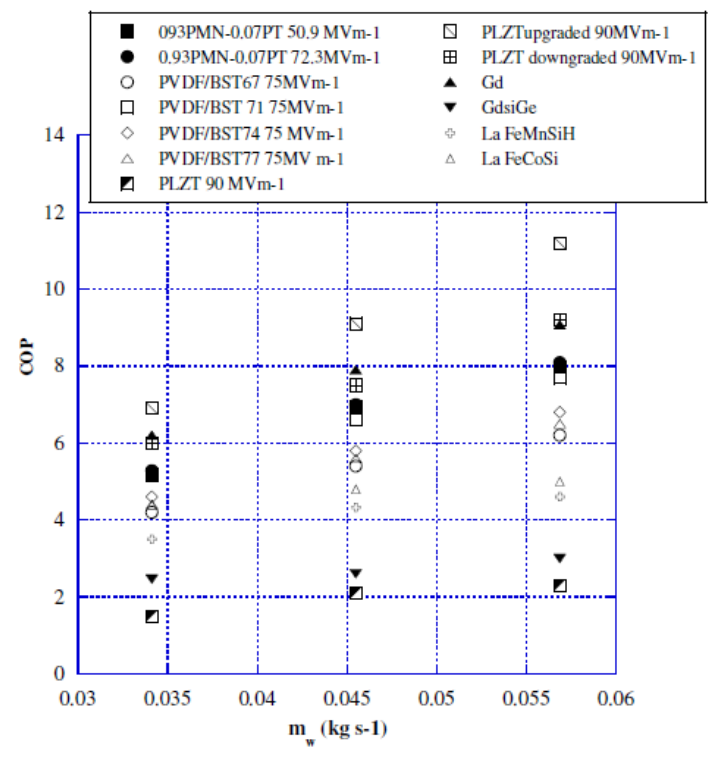

Figure 13. COP evaluated for different materials with respect to fluid flow rate in the $292 \div 300 \mathrm{~K}$ temperature range 


\section{CONCLUSIONS}

In this paper, the attention now is focused to the nonvapour-compression technologies for refrigeration and air conditioning. Among these technologies, there are the solid state cooling methods which embrace magnetocaloric and electrocaloric refrigeration. This paper aims to exhibit a comparison between such two technologies in terms of energetic performances under the same operating conditions. To this aim, a 2D model of an AMR/AER parallel plates regenerator has been developed. The results presented have been generated in the AMR cycle, for a magnetic induction, which varies from 0 to $1.5 \mathrm{~T}$. For the AER cycle different electric fields have been evaluated, by varying the intensity from 0 to $90 \mathrm{MVm}-1$. In all the simulations carried out the cycle frequency is $1.25 \mathrm{~Hz}$ and the secondary fluid is deionized water that flows in the interstitial channels formed by stacking the plates. Two temperature ranges have been investigated: $287 \div 295 \mathrm{~K}$ and $292 \div 300 \mathrm{~K}$. A number of AMR/AER cycles with different MMs/EMs employed as a refrigerant were simulated. The numerical results produced are: temperature span, refrigeration power and coefficient of performance. The materials kept under investigation have been: $\mathrm{Gd}, \mathrm{Gd}_{5} \mathrm{Si}_{2} \mathrm{Ge}_{2}, \mathrm{LaFe}_{11.384} \mathrm{Mn}_{0.356} \mathrm{Si}_{1.26} \mathrm{H}_{1.52}, \mathrm{LaFe}_{11.05}$ $\mathrm{Co}_{0.94} \mathrm{Si}_{1.10}, \mathrm{P}(\mathrm{VDF}-\mathrm{TrFE}-\mathrm{CFE}) / \mathrm{BST} 67, \mathrm{P}(\mathrm{VDF}-\mathrm{TrFE}-\mathrm{CFE}) /$ BST71, P(VDF-TrFE-CFE)/BST74, P(VDF-TrFE-CFE)/ BST77, 0.93PMN-0.07PT, PLZT11/85/15, PLZT up-graded and down-graded.From the simulations the following conclusions can be drawn: (1) the behavior of the EMs is poorly affected by the temperature range. Indeed, the EM materials have a significant electrocaloric effect in a wider temperature range if compared with MM materials. (2) The best materials for solid state refrigeration are the compositionally graded structures of PLZT thin films that give the best values in terms of temperature span (around 23 $24 \mathrm{~K}$ ), refrigeration power (with the best value of $893 \mathrm{~W}$ ) and COP (with the best value of 11.2). With these materials, an AER cycle can successfully over-performs AMR cycles (with mean values of: $+110 \%$ in term of $\Delta$ Tspan and more $+600 \%$ in term of $\mathrm{Q}_{\text {ref }}$ ) and can be an eco- friendly technology in solid state refrigeration. (3) Among the single composition other useful EM materials, although they exhibit a significant lower refrigerant power, are PVDF/BST polymer nanocomposities and PLZT with a single composition. In the temperature range $287 \div 295 \mathrm{~K}$ the best $\mathrm{MM}$ is $\mathrm{Gd}$, with a refrigerant power lower than that of $\mathrm{PVDF} / \mathrm{BST}$ polymer nanocomposities (around -51\%) and PLZT with a single composition (around $-49 \%$ ). In the range $292 \div 300 \mathrm{~K}$ the best $\mathrm{MM}$ is $\mathrm{Gd}_{5} \mathrm{Si}_{2} \mathrm{Ge}_{2}$ although its $\mathrm{Q}_{\text {ref values are lower than that }}$ of PLZT single composition (around of $-49 \%$ ) and that of PVDF/BST polymer (around -60\%). (4) In terms of COP, in the range $287 \div 295 \mathrm{~K}$, the highest values are those pertaining to $\mathrm{Gd}_{5} \mathrm{Si}_{2} \mathrm{Ge}_{2}$ (between 8.7 and 10 ). In the range $292 \div 300 \mathrm{~K}$ the highest values are those pertaining to PLZT with the upgraded composition (between 6.9 and 11.2). The single composition PLZT EM shows low COP values because of its great electric power due to a low electrical resistivity. (5) The worst performing materials are $\mathrm{LaFe}_{11.384} \mathrm{Mn}_{0.356} \mathrm{Si}_{1.26} \mathrm{H}_{1.52}$.

These results indicate that electrocaloric refrigeration can be a promising technology in solid state refrigeration. An AER cycle always shows better energetic performances than an AMR cycle working in the same operating conditions. Other advantages of the AER cycle are: the greater easiness and less expensiveness in obtaining high electric fields required for ECE with respect to generating magnetic fields (a large variation of the electric field can be obtained by simply charging and discharging an EM capacitor); the real simpleness in realizing a miniaturized refrigerator based on ECE; the remarkable cheapness and aviabilitiness of EM materials with respect to MM materials; the wideness of temperature working range of EM materials; the negligiblness of vibrations and the absence of moving parts during AER operations.

\section{REFERENCES}

[1] Montreal Protocol on substances that deplete the ozone layer, United Nation Environment Program (UN), New York, NY, USA, 1987.

[2] Mirandola A., Lorenzini E. (2016). Energy, Environment and Climate: From the Past to the Future, Int. J. of Heat and Technology, Vol. 34, No. 2, pp. 159-164. DOI: 10.18280/ijht.340201

[3] Kyoto Protocol to the United Nations Framework Convention on Climate Change, Kyoto, JPN, 1997.

[4] Aprea, C., Greco, A., Maiorino, A., Masselli, C., Metallo, A. (2016). HFO1234yf as a Drop-in Replacement for R134a in Domestic Refrigerators: A Life Cycle Climate Performance Analysis, Int. J. of Heat and Technology, Vol. 34, No. Special Issue 2, pp. S212-218. DOI: 10.18280/ijht.34S204

[5] Kitanovski, A., Plaznik, U., Tomc, U., Poredos, A. (2015). Present and future refrigeration and heat pump technologies, Int. J. of Refrig., Vol. 57, pp.288-298. DOI: $10.1016 /$ j.ijrefrig.2015.06.008

[6] Singh, J. K., Joshi, N., Ghousia Begum, S. (2016). Unsteady Magnetohydrodynamic Couette-Poiseuille Flow within Porous Plates Filled with Porous Medium in the Presence of a Moving Magnetic Field with Hall and Ion-slip Effects, Int. J. of Heat and Technology, Vol. 34, No. 1, pp. 89-97. DOI: 10.18280/ijht.340113

[7] Yu, B.F., Gao, Q., Zhang, B., Meng, X.Z., Chen, Z. (2003). Review on research of room temperature magnetic refrigeration, Int. Journ. of Refrig., Vol. 26, No. 6, pp. 622-636. DOI: 10.1016/S01407007(03)00048-3

[8] Yu, B.F., Liu, M., Egolf, P.W., Kitanovski, A. (2010). A review of magnetic refrigerator and heat pumps prototypes built before the year 2010, Int. Journ. of Refrig., Vol. 33, No. 6, pp. 1029-1060. DOI: 10.1016/j.ijrefrig.2010.04.002

[9] Kitanovski, A., Egolf, P.W. (2006). Thermodynamics of magnetic refrigeration, Int. Journ. of Refrig., Vol.29, No. 1, pp. 3-21. DOI: 10.1016/j.ijrefrig.2005.04.007

[10] Ozbolt, M., Kitanovski, A., Tusek, J., Poredos, T. (2014) Electrocaloric refrigeration: Thermodynamics, stat of the art and future perspectives, Int. J. of Refrig., Vol. 40, pp. 174-188. DOI: 10.1016/j.ijrefrig.2013.11.007

[11] Kawanami, T., Hirano, S., Fumoto, K., Hirasawa, S. (2011). Evaluation of fundamental performance on magnetocaloric cooling with active magnetic refrigerator, Appl. Therm. Eng., Vol. 31, No. 6-7, pp. 1176-1183.

DOI: 10.1016/j.applthermaleng.2010.12.017

[12] Zimm, C., Jastrab, A., Sternberg, A., Pecharsky, V.K., Gschneidner Jr., K.A., Osborne, M., Anderson, I. (1998). Description, performance of a near-room 
temperature magnetic refrigerator, Adv. Cryog. Eng., Vol. 4, pp. 1759-66. DOI: 10.1007/978-1-4757-9047$\underline{4} 2222$

[13] Suchaneck, G., Gerlach, G. (2015). Materials and device concepts for electrocaloric refrigeration. Physica Scripta, Vol. 90, No. 9, pp. 094020. DOI: 10.1088/0031-8949/90/9/094020

[14] Pakhomov, O.V., Karmanenko, S.F., Semenov, A.A. Starkov, A. S. and Es'kov, A. V. (2010) Thermodynamic estimation of cooling efficiency using an electrocaloric solid-state line. Technical Physics, Vol. 55, No. 8, pp. 1155-1160. DOI: 10.1134/S106378421008013X

[15] Vuarnoz, D. and Kawanami, T. (2013). Experimental validation of a coupled magneto-thermal model for a flat parallel-plate active magnetic regenerator, Appl. Therm. Eng., Vol. 54, No. 2, pp. 433-439. DOI: 10.1016/i.applthermaleng.2013.01.007

[16] Plaznik, U., Tušek, J., Kitanovski, A. and Poredoš, A. (2013). Numerical and experimental analysis of different magnetic thermodynamic cycles with active magnetic regenerator, Appl. Therm. Eng., Vol. 59, No. 1-2, pp. 52-59. DOI: 10.1016/j.applthermaleng.2013.05.019

[17] Aprea, C., Greco, A. and Maiorino, A. (2011). A numerical analysis of an Active Magnetic Regenerative Cascade system, Int. J. En. Res., Vol.35, No. 3, pp 177-188. DOI: $\underline{10.1002 / e r .1682}$

[18] Aprea, C., Greco, A. and Maiorino, A. (2011). A numerical analysis of an Active Magnetic Regenerative Refrigerant system with a multi-layer regenerator, En Con. Man., Vol. 52, No. 1, pp. 97-107. DOI: 10.1016/j.enconman.2010.06.048

[19] Aprea, C., Greco, A. and Maiorino, A. (2012). Modelling an Active Magnetic Refrigeration system: a comparison with different models of incompressible flow through a packed bed, Appl. Therm. Eng., Vol. 36, No. 1, pp. 296-306. DOI 10.1016/j.applthermaleng.2011.10.034

[20] Aprea, C., Greco, A. and Maiorino, A. (2013). The use of the first and of the second order phase magnetic transition alloys for an AMR refrigerator at room temperature: a numerical analysis of the energy performances En. Con. Man., Vol. 70, pp. 40-55. DOI: 10.1016/j.enconman.2013.02.006

[21] Aprea, C., Greco, A. and Maiorino, A. (2013). A dimensionless numerical analysis for the optimization of an AMR cycle Int. J. En. Res., Vol. 37, No. 12, pp 1475-1487. DOI: $10.1002 / \mathrm{er} .2955$

[22] Aprea, C., Greco, A., Maiorino, A. and Masselli, C. (2015) A comparison between experimental and 2D numerical results of a packed-bed active magnetic Regenerator, Appl. Therm. Eng., Vol. 90, pp. 376-383. DOI: 10.1016/j.applthermaleng.2015.07.020

[23] Aprea, C., Greco, A., Maiorino, A. and Masselli, C. (2015) A comparison between rare earth and transition metals working as magnetic materials in an AMR refrigerator in the room temperature range, Appl. Therm. Eng., Vol. 91, pp. 767-777. DOI: 10.1016/j.applthermaleng.2015.08.083

[24] Benford, S.M. and Brown, G.V. (1981). T-S diagram for gadolinium near the Curie temperature, J. Appl. Phys., Vol. 52, No. 3, pp. 2110-2112. DOI: 10.1063/1.329633

[25] Ponomarev, B.K. (1986). Magnetic properties of gadolinium in the region of paraprocess, J. Magn.
Magn. Mater., Vol. 61, pp. 129-138. DOI: 10.1016/0304-8853(86)90075-2

[26] Foldeaki, M., Schnelle, W., Gmelin, E., Benard, P., Koszegi, B., Giguere, A., Chahine, R. and Bose, T.K. (1997). Comparison of magnetocaloric properties from magnetic and thermal measurements, J. Appl. Phys., Vol. 82, No. 1, pp. 309-316. DOI: $10.1063 / 1.365813$

[27] Dan'kov, S.Y., Spichkin, Y.I. and Thishin, A.M. (1996). Magnetic entropy and phase transitions in Gd, Tb, Dy and Ho, J. Magn. Magn. Mater., Vol. 152, No. 1-2, pp. 208-12. DOI: $10.1016 / 0304-8853(95) 00427-0$

[28] Dan'kov, S.Y. and Thishin, A.M. (1998). Magnetic phase transitions and the magnetothermal properties of gadolinium, Phys. Rev. B, Vol. 57, No. 6, pp. 34783489. DOI: $10.1103 /$ PhysRevB.57.3478

[29] Griffel, M., Skochdopole, R.E. and Spedding, F.H. (1954). The heat capacity of gadolinium from 15 to 355 K, Phys. Rev., Vol. 93, No. 4, pp. 657-661. DOI: 10.1103/PhysRev.93.657

[30] Glorieux, C., Thoen, J., Bednarz, G., White, M.A. and Geldart, D.J.W. (1995). Photoacustic investigation of the temperature and magnetic field dependence of the specific heat-capacity and thermal conductivity near the Curie point of gadolinium, Phys. Rev. B, Vol. 52, No. 17, pp. 12770-12778. DOI: 10.1103/PhysRevB.52.12770

[31] Pecharsky, V.K. and Gschneidner Jr., K.A. (1997). Effect of alloying on the giant magnetocaloric effect of $\mathrm{Gd}_{5} \mathrm{Si}_{2} \mathrm{Ge}_{2}$, J. Magn. Magn. Mat., Vol. 167, No. 3, pp. 179-184. DOI: 10.1016/S0304-8853(96)00759-7

[32] Pecharsky, V.K. and Gschneidner Jr., K.A. (1997). Giant magnetocaloric effect in $\mathrm{Gd}_{5} \mathrm{Si}_{2} \mathrm{Ge}_{2}$, Phys. Rev. Lett., Vol. 78, No. 23, pp. 4494-4497. DOI: 10.1103/PhysRevLett.78.4494

[33] Pecharsky, V.K., Samolyuk, G.D., Antropov, V.P., Pecharsky, A.O. and Gschneidner Jr., K.A. (2003). The effect of varying the crystal structure on the magnetism, electronic structure and thermodynamics in the $\mathrm{Gd}_{5}\left(\mathrm{Si}_{\mathrm{x}} \mathrm{Ge}_{1-\mathrm{x}}\right)_{4}$ alloys for $1.4<\mathrm{x}<2.2$, J. Magn. Magn. Mat., Vol. 267, pp. 60-68. DOI: 10.1016/S0022-4596(02)00146-9

[34] Burriel, R., Sazatornil, M., Palacios, E., Barcza, A. and Katter, M. (2014). Accurate determination of the magnetocaloric parameters of $\mathrm{LaFeCoSi}$ compounds, 6th IIF-IIR Int. Conf. on Magnetic Refrigeration, Victoria, BC

[35] Morrison, K., Sandeman, K.G., Cohen, L.F., Sasso, C.P., Basso, V., Barcza, A., Katter, M., Moore, J.D., Skokov, K.P. and Gutfleisch, O. (2012). Evaluation of the reliability of the measurement of key magnetocaloric properties: A round robin study of $\mathrm{La}(\mathrm{Fe}, \mathrm{Si}, \mathrm{Mn}) \mathrm{H} \delta$ conducted by the SSEEC consortium of European laboratories, Int. J. Refrig., Vol. 35, No. 6, pp. 1528-1536. DOI: 10.1016/j.ijrefrig.2012.04.001

[36] Bjørk, R., Bahl, C.R.H. and Katter, M. (2010). Magnetocaloric properties of $\mathrm{LaFe} 13-\mathrm{x}-\mathrm{y}$ Co x Si y and commercial grade Gd, J. Magn. Magn. Mat., Vol. 322, No. 24, pp. 3882-3888. DOI: 10.1016/j.jmmm.2010.08.013

[37] Li, X., Qian, X.S., Lu, S.G., Cheng, J., Fang, Z. and Zhang, Q.M. (2011). Tunable temperature dependence of electrocaloric effect in ferroelectric relaxor poly (vinylidene fluoride-trifluoroethylenechlorofluoroethylene terpolymer. Appl. Phys. Lett., Vol. 99, No. 5, pp. 052907. DOI: 10.1063/1.3624533 
[38] Zhang, G., Li Q., Gu, H., Jiang, S., Han, K., Gadinski, R., Haque, A., Zhang, Q. and Wang Q. (2015). Ferroelectric polymer nanocomposities for room temperature elcetrocaloric refrigeration, Adv. Mat., Vol. 27, No. 8, pp. 1450-1454. DOI: $\underline{10.1002 / \mathrm{adma} .201404591}$

[39] Correia, T.M., Young, J.S., Whatmore, R.W., Scott J.F., Mathur, N.D. and Zhang, Q. (2009). Investigation of the electrocaloric effect in a $\mathrm{PbMg}_{2 / 3} \mathrm{Nb}_{1 / 3} \mathrm{O}_{3}$ $\mathrm{PbTiO}_{3}$, Appl. Phys. Lett., Vol. 95, No. 18, pp. 182904. DOI: $10.1063 / 1.3257695$

[40] Hamad, M.A. (2013). Room temperature giant electrocaloric properties of relaxor ferroelectric 0.93 PMN-0.07 PT thin film. AIP Advances, Vol. 3, No. 3, pp. 032115. DOI: $\underline{10.1063 / 1.4795156}$

[41] Zhao, Y., Hao, X. and Zhang, Q. (2016). Enhanced energy-storage performance and electrocaloric effect in compositionally graded $\mathrm{Pb}_{(1-3 / 2 \mathrm{x})} \mathrm{La}_{\mathrm{x}} \mathrm{Zr}_{0.85} \mathrm{Ti}_{0.15} \mathrm{O}_{3}$, Ceram. Int., Vol. 42, No. 1, pp. 1679-1687. DOI: 10.1016/j.ceramint.2015.09.122

[42] Wood, M.E. and Potter, W.H. (1985). General analysis of magnetic refrigeration and its optimization using a new concept: maximization of refrigerant capacity, Cryog., Vol. 25, No. 12, pp. 667-683. DOI: 10.1016/0011-2275(85)90187-0

[43] Ozbolt, M., Kitanovski, A., Tusek, J. and Poredos, A. (2014) Electrocaloric vs. magnetocaloric energy conversion, Int. J. Refrig., Vol. 37, pp. 16-27. DOI: 10.1016/j.ijrefrig.2013.07.001

[44] Aprea, C., Greco, A., Maiorino, A. and Masselli, C. (2016), The energy performances of a rotary permanent magnet magnetic refrigerator, Int. J. Refrig., Vol. 61, pp. 1-11. DOI: 10.1016/j.ijrefrig.2015.09.005

[45] Tagliafico, L.A., Scarpa F., Valsuani, F. and Tagliafico G. (2013). Preliminary experimental results from a linear reciprocating magnetic refrigerator prototype, Appl. Therm. Eng., Vol. 52, No. 2, pp. 492497. DOI: $10.1016 /$ j.applthermaleng.2012.12.022

[46] Aprea, C., Greco, A., Maiorino, A., Mastrullo, R. and Tura, A. (2014). Initial experimental results from a rotary permanent magnet magnetic refrigerator, Int. $J$. Refrig., Vol. 43, pp.111-122. DOI: $\underline{\text { 10.1016/j.ijrefrig.2014.03.014 }}$

[47] Aprea, C., Greco, A., Maiorino, A. and Masselli, C. (2015). Magnetic refrigeration: an eco-friendly technology for the refrigeration at room temperature, $J$. Phys.: Conf. Ser., Vol. 655, pp. 012026. DOI: 10.1088/1742-6596/655/1/012026

[48] Aprea, C., Greco, A., Maiorino, A. and Masselli, C. (2016). A rotary permanent magnet magnetic refrigerator based on AMR cycle, Appl. Therm. Eng., Vol. 101, pp. 699-703. DOI: 10.1016/j.applthermaleng.2016.01.09

[49] Aprea, C., Greco, A., Maiorino, A. and Masselli, C. (2016). A comparison between different materials in an active electrocaloric regenerative cycle with a $2 \mathrm{D}$ numerical model, Int. J. Refrig., Vol. 69, pp. 369-382. DOI: $10.1016 /$ j.ijrefrig.2016.06.016

[50] Guo, D., Gao, J., Mcgaughey, A.J.M., Fedder, G.K., Moran, M. and Yao S.C. (2013). Design and evaluation of a MEMS-based Stirling microcooler, $J$. H. Trans., Vol. 135, No. 11, pp. 111003. DOI: $\underline{10.1115 / 1.4024596}$

\section{NOMENCLATURE}

B

C

$\mathrm{E}$

$\mathrm{H}$

$\mathrm{k}$

$\mathrm{m}$

M

$\mathrm{p}$

$P$

Q

$\mathrm{S}$

$\mathrm{T}$

$\mathrm{U}$

$\mathrm{V}$

W

$\mathrm{X}$

$\mathrm{y}$

\section{Greek symbols}

$\delta$

$\Delta$

$\eta$

$\mu$

v

$\rho$

$\tau$

\section{Subscripts}

$\begin{array}{ll}\text { ad } & \text { adiabatic } \\ \text { B } & \text { breakdown } \\ \text { C } & \text { Cold } \\ \text { CF } & \text { cold fluid flow } \\ \text { D } & \text { depolarization/demagnetization phase } \\ \text { E } & \text { constant electric field } \\ \text { El } & \text { electronic } \\ \text { F } & \text { fluid } \\ \text { FHWM } & \text { full half width modulation } \\ \text { H } & \text { hot } \\ \text { HF } & \text { hot fluid flow } \\ \text { M } & \text { magnetization phase } \\ \text { M } & \text { magnetic } \\ \text { max } & \text { maximum } \\ \text { P } & \text { polarization phase } \\ \text { ref } & \text { refrigerant } \\ \text { rej } & \text { rejected } \\ \text { S } & \text { constant entropy } \\ \text { S } & \text { solid } \\ \text { T } & \text { constant temperature } \\ \text { W } & \text { water }\end{array}$

\author{
magnetic field induction, $\mathrm{T}$ \\ specific heat, J. kg-1. K-1 \\ electric field intensity, V. m-1 \\ magnetic field intensity, A. m-1 \\ thermal conductivity, W. m-1. K-1 \\ fluid flow rate, $\mathrm{kg}$. s-1 \\ magnetization, A. m-1 \\ pressure, $\mathrm{Pa}$ \\ polarization, C.m-2 \\ thermal power, $\mathrm{W}$ \\ entropy, J. K-1 \\ temperature, $\mathrm{K}$ \\ longitudinal velocity, m.s-1 \\ orthogonal velocity, m.s-1 \\ work, J \\ longitudinal spatial coordinate, $\mathrm{m}$ \\ orthogonal spatial coordinate, $\mathrm{m}$
}

thermal penetration depth, $\mathrm{mm}$

finite difference

isentropic efficiency

dynamic viscosity, kg. m-1.s-1

cinematic viscosity, $\mathrm{m} 2$. s-1

density, kg. m-3

period of each phase cycle, $\mathrm{s}$ 